\title{
4D Printing of Resorbable Complex Shape Memory Poly(propylene fumarate) Star Scaffolds
}

Gaëlle Le Ferland Matthew L. Becker*1,2,3

${ }^{1}$ Department of Polymer Science, The University of Akron, Akron, Ohio 44325, USA

${ }^{2}$ Department of Chemistry, Duke University, Durham, NC 27708, USA

${ }^{3}$ Department of Mechanical Engineering and Material Science, Duke University, Durham, NC 27708, USA

*Corresponding Author: E-mail: matthew.l.becker@duke.edu 
Table S1. Characterization summary of gyroid scaffolds obtained by DLP 3D printing

\begin{tabular}{cccc}
\cline { 2 - 4 } & $\begin{array}{c}\text { Strut size } \\
(\mu \mathrm{m})^{\mathrm{a}}\end{array}$ & $\begin{array}{c}\text { Porosity } \\
(\%)^{\mathrm{b}}\end{array}$ & $\begin{array}{c}\text { Pore size } \\
(\mu \mathrm{m})^{\mathrm{c}}\end{array}$ \\
\hline CAD model 1 & 140 & 88.2 & 489 \\
Linear PPF DP10 & $131( \pm 11)$ & 85.2 & 389 \\
Star PPF DP40 & $142( \pm 10)$ & 90.5 & 575 \\
Star PPF DP200 & $141( \pm 9)$ & 90.8 & 583 \\
\hline CAD model 2 & 200 & 88.2 & 699 \\
Linear PPF DP10 & $246( \pm 54)$ & 81.2 & 613 \\
Star PPF DP40 & $194( \pm 13)$ & 88.1 & 674 \\
Star PPF DP200 & $196( \pm 12)$ & 86.3 & 616 \\
\hline CAD model 3 & 240 & 88.2 & 838 \\
Linear PPF DP10 & $242( \pm 26)$ & 77.9 & 532 \\
Star PPF DP40 & $238( \pm 17)$ & 87.3 & 790 \\
Star PPF DP200 & $237( \pm 11)$ & 88.3 & 833 \\
\hline CAD model 4 & 280 & 88.2 & 978 \\
Linear PPF DP10 & $393( \pm 37)$ & 80.5 & 952 \\
Star PPF DP40 & $286( \pm 24)$ & 87.8 & 976 \\
Star PPF DP200 & $275( \pm 11)$ & 87.6 & 928 \\
\hline
\end{tabular}

a obtained by optical microscopy, analyses using ImageJ software based on two scaffolds and 30

measurements. ${ }^{\mathrm{b}}$ obtained by $\mu-\mathrm{CT} .{ }^{\mathrm{c}}$ calculated. 

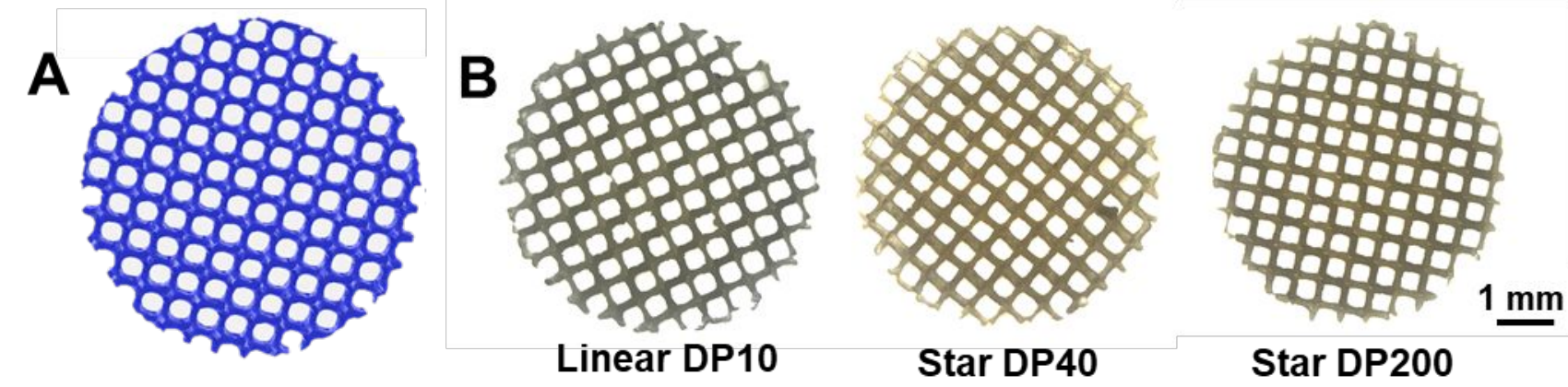

Star DP40

Star DP200
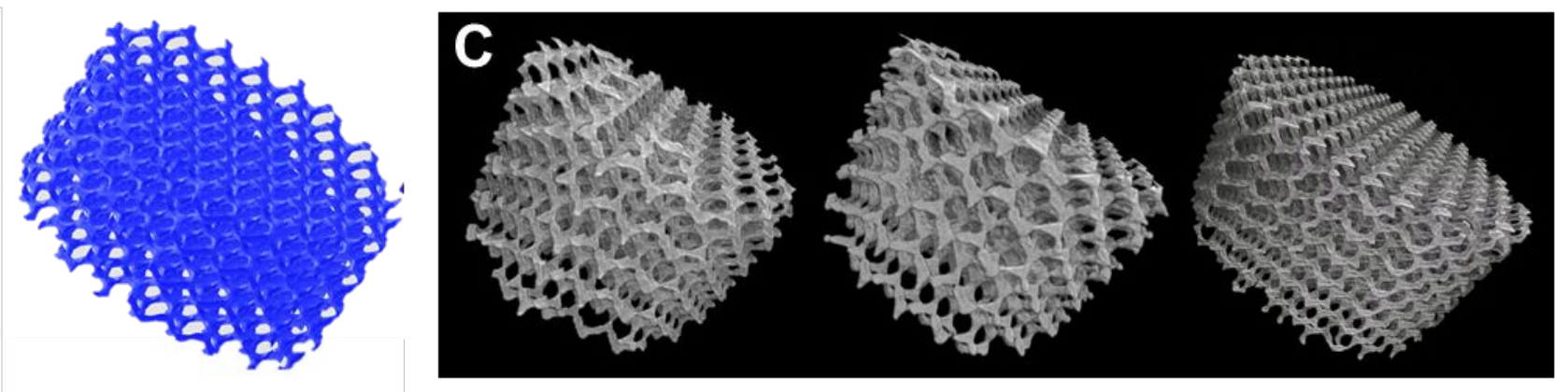

Figure S1. (A) CAD file was created in Matlab using the Schoen gyroid triply periodic minimal surface with $140 \mu \mathrm{m}$ strut size, $489 \mu \mathrm{m}$ pore size, and $88.2 \%$ porosity. (B) Optical micrographs of the top of the scaffolds obtained from the different PPF (from left to right: linear PPF DP10, star PPF DP40, star PPF DP200). (C) $\mu$-CT images of the scaffolds obtained from the different PPF (from left to right: linear PPF DP10, star PPF DP40, star PPF DP200). 

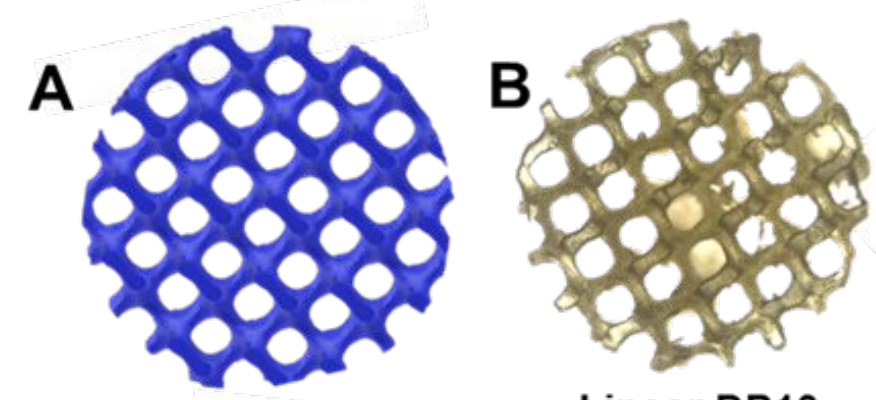

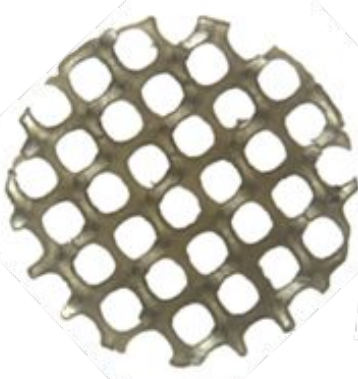

Star DP40

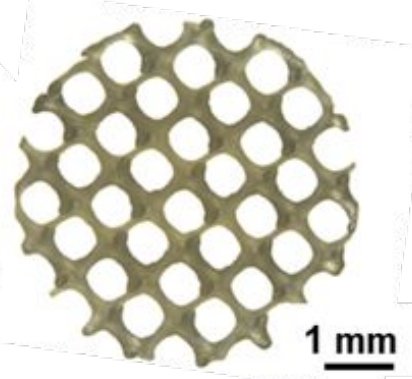

Star DP200
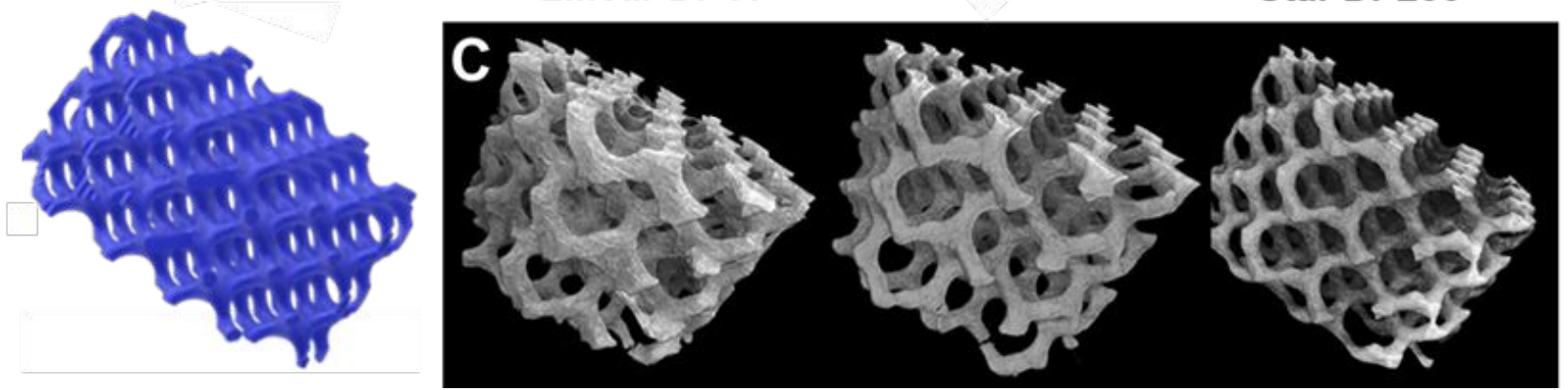

Figure S2. (A) CAD file was created in Matlab using the Schoen gyroid triply periodic minimal surface with $240 \mu \mathrm{m}$ strut size, $838 \mu \mathrm{m}$ pore size, and $88.2 \%$ porosity. (B) Optical micrographs of the top of the scaffolds obtained from the different PPF (from left to right: linear PPF DP10, star PPF DP40, star PPF DP200). (C) $\mu$-CT images of the scaffolds obtained from the different PPF (from left to right: linear PPF DP10, star PPF DP40, star PPF DP200). 

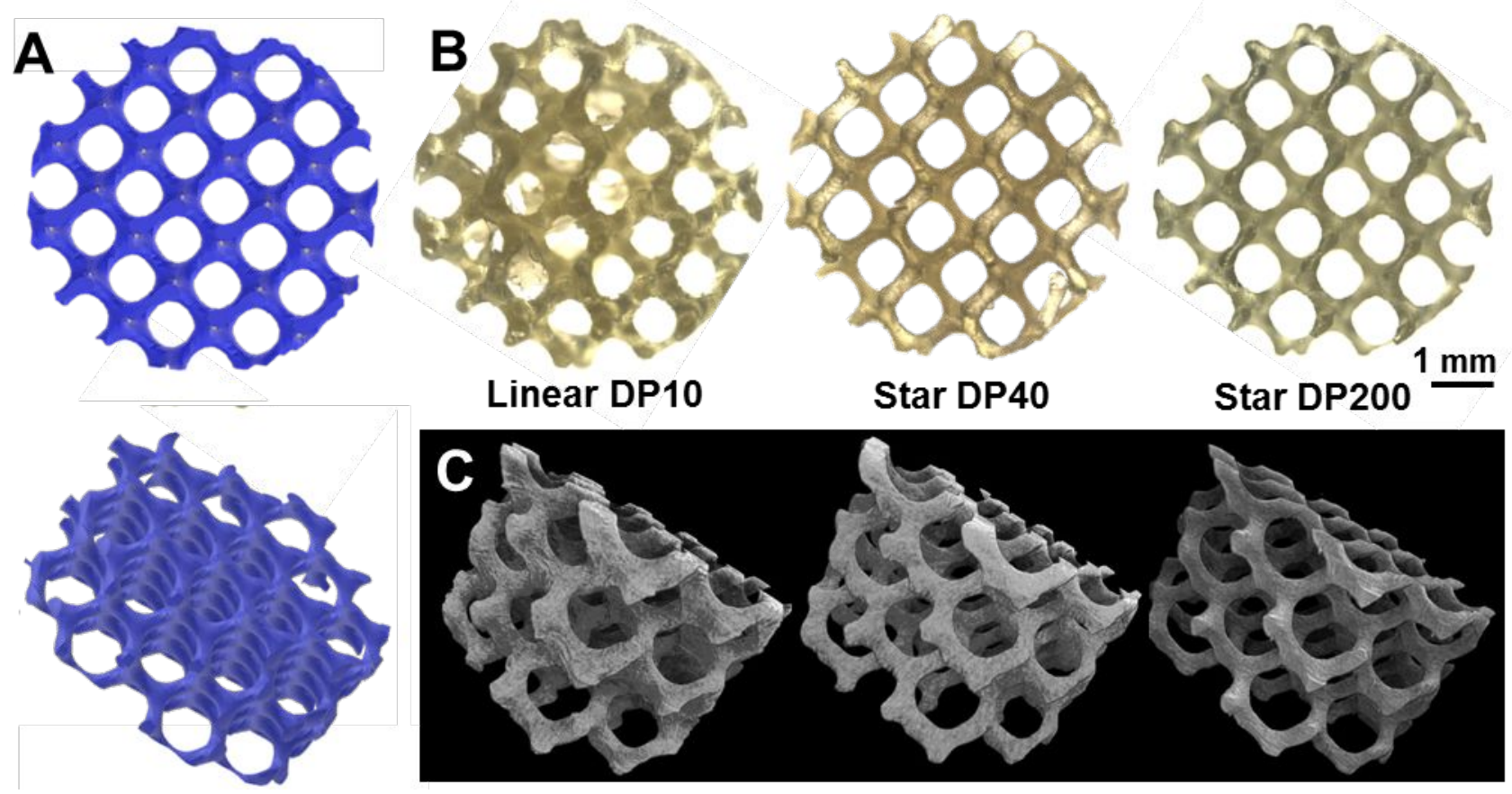

Figure S3. (A) CAD file was created in Matlab using the Schoen gyroid triply periodic minimal surface with $280 \mu \mathrm{m}$ strut size, $978 \mu \mathrm{m}$ pore size, and $88.2 \%$ porosity. (B) Optical micrographs of the top of the scaffolds obtained from the different PPF (from left to right: linear PPF DP10, star PPF DP40, star PPF DP200). (C) $\mu$-CT images of the scaffolds obtained from the different PPF (from left to right: linear PPF DP10, star PPF DP40, star PPF DP200). 
B

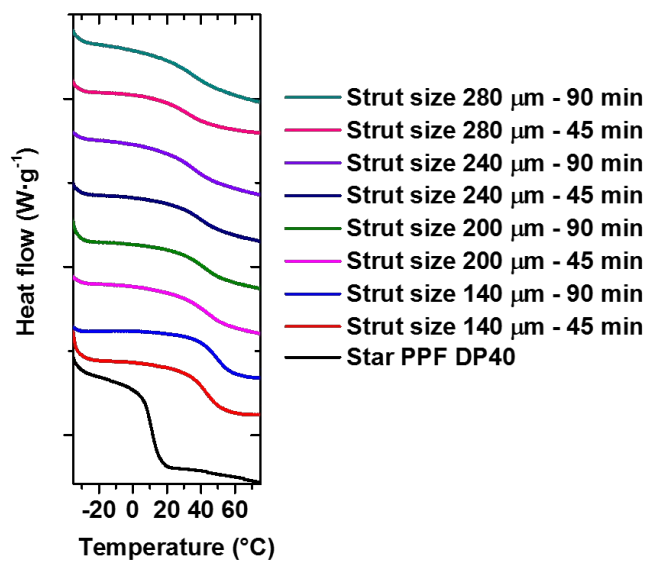

Star PPF DP40

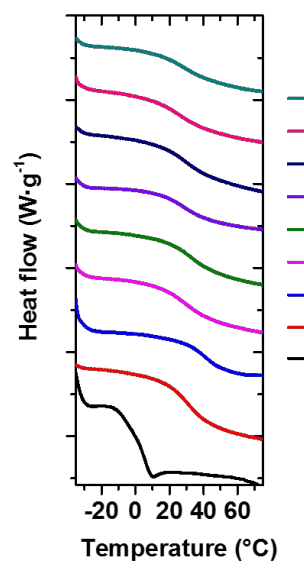

— Strut size $280 \mu \mathrm{m}$ - $90 \mathrm{~min}$ Strut size $280 \mu \mathrm{m}$ - $45 \mathrm{~min}$ Strut size $240 \mu \mathrm{m}-90 \mathrm{~min}$ Strut size $240 \mu \mathrm{m}-45 \mathrm{~min}$ Strut size $200 \mu \mathrm{m}$ - $90 \mathrm{~min}$ Strut size $200 \mu \mathrm{m}$ - $45 \mathrm{~min}$ Strut size $140 \mu \mathrm{m}$ - $90 \mathrm{~min}$ Strut size $140 \mu \mathrm{m}$ - $45 \mathrm{~min}$ — Linear DP10

c Star PPF DP200

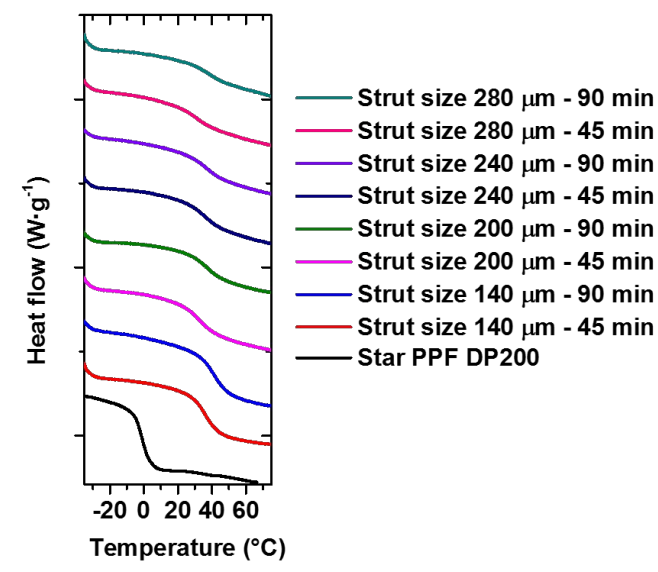

Figure S4. Differential scanning calorimetry (DSC) traces for PPF polymers and corresponding scaffolds of various strut sizes and after different post-curing times: (A) linear PPF DP10, (B) star PPF DP40, (C) star PPF DP200. Temperature scan rate was $10^{\circ} \mathrm{C} \cdot \mathrm{min}^{-1}$. 